problem," says Blackstock.

The ETC Group, an advocacy organization based in Ottawa that has led a global drive against geoengineering, has suggested that George misrepresented the project's potential to generate carbon credits. Documents from the Old Massett website imply that in raising funds, project leaders stressed the potential for easy carbon credits. One document, tied to a 2011 loan application, showed that bank managers were wary of the HSRC's claims that the market for such carbon offsets was proven and that "retail outlets and banks in Germany are begging for the product".

In fact, carbon credits from iron-fertilization projects cannot be offered on formal markets such as the European emissions trading system, although willing buyers might be found outside those markets. And whether iron fertilization actually sequesters carbon is uncertain. A study ${ }^{1}$ by Smetacek published in July — based on analysis of an experiment in 2004 - found that at least half of the carbon taken up by the iron-fertilized plankton was buried after they sank to the bottom of the sea. But other studies ${ }^{2}$ have found that carbon in the blooms remains in the active biological cycle and is not sequestered at all.

George says that the bankers were ultimately satisfied, and that carbon credits are no more than a possible source of future funding, if the science supports them. But in an initial interview, Disney repeatedly said that the company needs to sell the carbon credits quickly to repay its loan from the community. "Being the guy who sold this to the community, I bloody well better come up with the money," he said. Disney later backed off his emphasis on carbon credits and stressed that he stands by George.

It is unclear whether the project will restore the salmon. A bumper run of sockeye salmon (Oncorhynchus nerka) in 2010 came two years after a volcanic eruption in Alaska sent a layer of iron-rich ash over the ocean, fertilizing a plankton bloom ${ }^{3}$. But many scientists remain sceptical.

Whether the Haida experiment worked won't be known for two years, when the youngest of the salmon feeding in the ocean today return home to spawn. John Nightingale, president of the Vancouver Aquarium in Canada, says that will be a chance to glean some science from the project. The work may have lacked scientific rigour, he says, but the HSRC has now agreed to make all of its data available to scientists. It has "done something unique", Nightingale says. "I want the maximum information, the maximum analysis, the maximum debate."

1. Smetacek, V. et al. Nature 487, 313-319 (2012).

2. Boyd, P. W. et al. Nature 407, 695-702 (2000).

3. Jones, N. Nature http://dx.doi.org/10.1038/ news.2010.572 (2010).

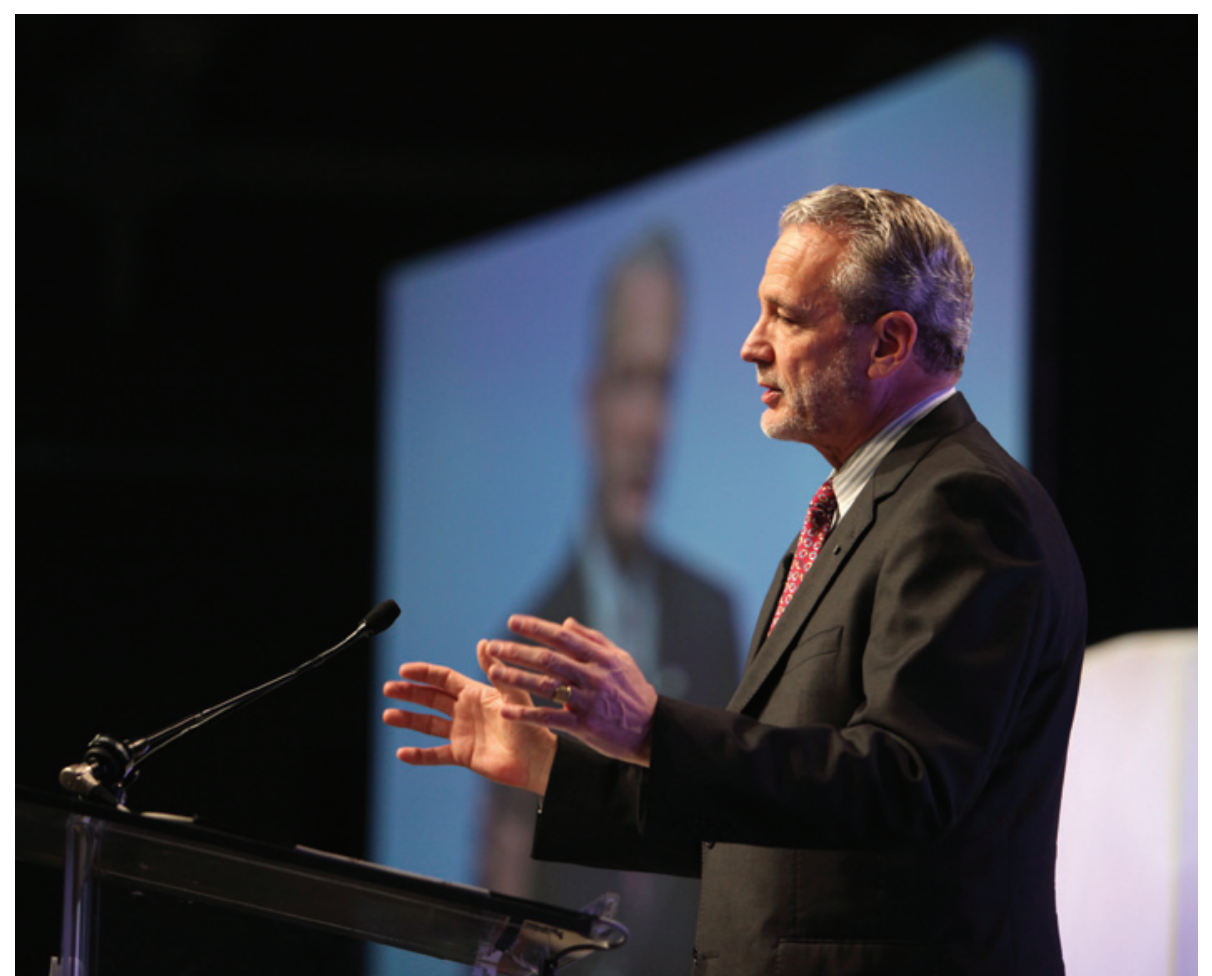

William Gimson of the Cancer Prevention and Research Institute of Texas is on the hunt for a chief scientist.

PEER REVIEW

\title{
Texas cancer fund seeks fresh start
}

\section{Critics question whether institute has resolved conflicts between commercial and scientific goals.}

\section{BY MONYA BAKER}

I t must be hard filling a position when the last person in the job was a Nobel laureate who quit in protest over a disregard for peer review, and whose departure triggered an avalanche of other resignations. Nevertheless, the Cancer Prevention and Research Institute of Texas (CPRIT) is confident that it will announce a chief scientific officer to replace Alfred Gilman, who departed on 12 October, by the end of the year. But institute watchers suspect that even an ideal candidate might not be able to dispel the science community's unease about the CPRIT's attempt to simultaneously support basic research and nurture companies.

"I can't think of a better example than this one of how a potential conflict of interest can undermine an institution," says Paul Root Wolpe, a bioethicist at Emory University in Atlanta, Georgia.

The Austin-based CPRIT was created in 2007 when Texas voters agreed to a US $\$ 3$-billion

initiative that would spend $\$ 300$ million a year to advance basic research, reduce cancer rates and nurture Texas companies. Since then, the state agency has awarded 427 grants totalling more than $\$ 750$ million, with $\$ 574$ million designated for scientific research and the rest for commercialization and prevention. Its funding of innovative research has won accolades.

Controversy erupted in May after Gilman, who won the 1994 medicine Nobel, tendered his resignation in a strongly worded letter criticizing a \$20-million commercial 'incubator' grant that had been awarded without scientific review. Much of the grant was slated for a group led by Lynda Chin at the University of Texas MD Anderson Cancer Center in Houston, where Chin's husband, Ronald

$\rightarrow$ NATURE.COM Read an interview with a former CPRIT scientific reviewer: go.nature.com/rxa4yl
DePinho, is president. CPRIT internal correspondence that was subsequently made public through freedom-ofinformation rules 
- suggests that the grant criteria were tailored to improve Chin's eligibility (see Nature 486, 169-170; 2012). At the same time as the incubator grant was awarded, a set of grants recommended for approval by the CPRIT's scientific council stalled.

Gilman said that he would remain with the CPRIT until the autumn. Over the summer, the contentious \$20-million grant was withdrawn for 're-review', and provisions were made for scientific review of all commercial grants. The previously sidelined grants were approved (as were all grants recommended by reviewers), and a compliance officer was hired to prevent submission irregularities.

But the measures to uphold peer review have not won over the CPRIT's critics, and many scientific reviewers, including at least seven of the eight heads of the institute's external scientific review panels, decided to depart along with Gilman. Their resignation letters accused the CPRIT of "hucksterism" and of having "dishonored" the system of peer review. They also complained of unusual circumstances faced by reviewers evaluating commercial proposals, saying that CPRIT staff sent them additional information and invited them to revise unfavourable scores. The resignation letters said that concerns they expressed were ignored, and Gilman himself suggests that CPRIT officials have been biding their

time, "waiting for me to get out of the way".

An e-mail from Jimmy Mansour, a Texas businessman who heads the CPRIT's governing board, to his fellow committee members said that he looked forward to the appointment of MD Anderson's provost, Raymond DuBois, in Gilman's place. "Gilman is gone and so is his influence," Mansour wrote last week in an e-mail made public by the Houston Chronicle on 18 October.

"I can't think of a better example than this one of how a potential conflict of interest can undermine an institution."

Mansour later told Nature that Gilman's peerreview system was a "cornerstone" of funding decisions. DuBois, for his part, says that he has not accepted a position at the CPRIT and is instead taking up a role at Arizona State University in Tempe.

William Gimson, the CPRIT's executive director, agrees that there were "process problems" with the grants, but denies more serious underlying issues. The concerns "mostly boil down to the natural conflict that exists between our scientific and commercialization portfolios", he says.

Such conflicts can undermine an institution, says Hamilton Moses at Alerion Advisors, a consulting firm for research institutes in North Garden, Virginia. "There are very few examples I can think of where adequate review has occurred when there has been an economic-development agenda."

Wolpe says that the CPRIT needs to take explicit action to restore trust between its overseers and its scientific reviewers. "The quickest way they can come back is through the resignation of the director," he says, a move that would signal a commitment to change. "Barring that, they need to put in a fully independent external review of their processes and procedures. And they need to announce very clear remedial measures." Gimson says that he has no plans to resign and that concerns about scientific integrity are unfounded.

Garnet Coleman, a member of the Texas House of Representatives, believes that the CPRIT's problems originated with the legislation that created the institute, which he says lacks appropriate internal safeguards and oversight by the legislature. "It was like somebody didn't know how to write the creation of a state agency, but they did anyway," he says. "We need to take the rules, fix them and put them in statute." He hopes to introduce a new measure next year.

Gilman, now retired, says that if the CPRIT cannot fund the best science, "I would personally rather see the money not spent and go back

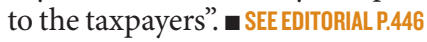

